\title{
Experimental and Simulation Study of Complex Structure Well Pattern Optimization for Buried Hill Fractured Reservoirs
}

\author{
Jian Liu · Yuetian Liu · Jichang Zhang · Jie Yang • \\ Zhengliang Guo
}

Received: 1 December 2013 / Accepted: 30 June 2014 / Published online: 11 October 2014

(C) The Author(s) 2014. This article is published with open access at Springerlink.com

\begin{abstract}
The use of a vertical well pattern results in productivity deficiency and poor development effect when developing buried hill reservoirs with complex properties. In this work, experiments are conducted to determine the best pattern for complex structure wells in buried hill reservoirs. Discretization is employed in an experimental method that uses unit cubic rocks with a size of $5 \mathrm{~cm} \times 5 \mathrm{~cm} \times 5 \mathrm{~cm}$. The rocks are bonded in a spotty or reticular design to form a macroscopic model. Based on water flooding similarity criteria of fractured reservoir, an experimental model similar to a quarter of a five-spot unit in an actual reservoir is designed and manufactured. By selectively plugging wells in the model, various well patterns are established. Simulation results indicate that the vertical-vertical well pattern exhibits the fastest water breakthrough, fastest increase in water cut, and lowest recovery under the same pressure difference and well spacing. The horizontal-horizontal well pattern has the slowest water cut increase and the highest final oil recovery. For fishbone wells, this pattern facilitates an ideal development effect when the percolation direction is perpendicular to the plane determined by the mother bore and branch. When liquid rate, water cut, and recovery are considered, the horizontal-horizontal well pattern is recommended when conditions allow.
\end{abstract}

J. Liu $(\varangle) \cdot$ Y. Liu $\cdot$ Z. Guo

MOE Key Laboratory of Petroleum Engineering

in China University of Petroleum, Beijing 102249, China

e-mail: kevenlj@163.com

J. Liu

Research Institute of Petroleum Exploration and Development,

Beijing 100083, China

J. Zhang · J. Yang

Shenyang Oil Plant of Liaohe Oilfield, Shenyang 110316, China
Keywords Fracture $\cdot$ Discretization $\cdot$ Similarity $\cdot$ Well pattern $\cdot$ Development effect

الخلاصـة

إن استخدام نمط البئر العمودي ينتج نقصا في الإنتاجية وفقر ا في تأثثر

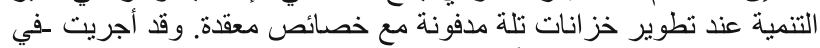

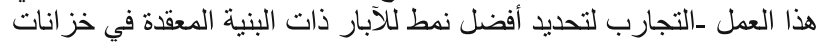

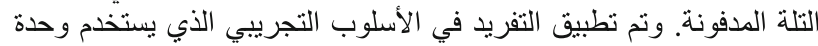

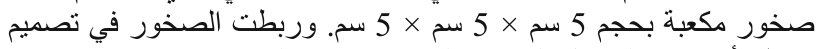

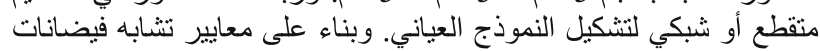

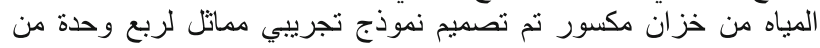

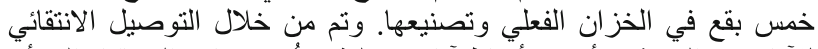

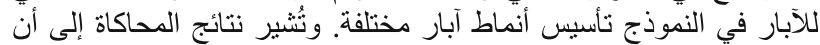

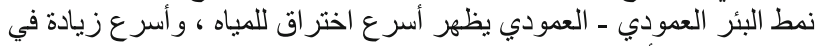

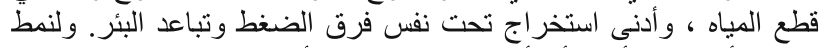

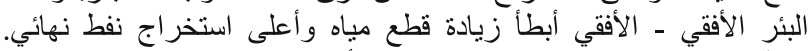

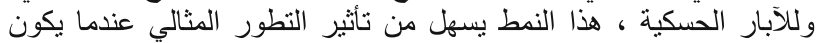

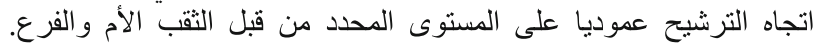

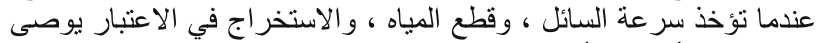

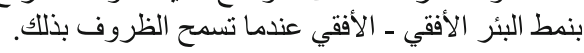

\section{Introduction}

The complex structure well technique that was developed in the twentieth century can reduce water and gas coning, improve the production of thin and fractured reservoirs, and contribute to higher oil and gas production while producing lower cost and greater economic benefit, especially in cases in which vertical wells are not economical.

Complex structure wells can generally be categorized into horizontal, fishbone, and multilateral wells. The benefit from the increase in production provided by a horizontal well is usually greater than the cost of drilling the horizontal 
section. Horizontal wells have been widely used by reservoir engineers since the end of the 1980s [1]. Fishbone well technology extends the horizontal section plane with a single horizontal wellbore to a plane with more than one horizontal wellbore, achieving a more exposed reservoir area and increasing well production [2]. Multilateral well technology improves well productivity by maximizing reservoir contact, resulting in a development with fewer wells while minimizing water and gas coning [3]. Multilateral well technology has been applied to increase the production rate per well [4].

\subsection{Theoretical Research}

As complex structure well technology became widely applied in oilfield development, an increasing number of theories and technologies have been developed for such wells. Mathematical models for multilateral well productivity prediction have been presented and modified [5-10], and parameters for the optimization of complex structure wells have been studied [11-13].

\subsection{Application}

Multilateral and fishbone wells have been applied in countries in the Middle East and South America, including the UAE, Saudi Arabia, Oman, Iran, Qatar, Kuwait, Bahrain, Iraq, and Venezuela [14,15]. For example, Saudi Aramco has drilled over 440 horizontal and maximum reservoir contact wells since 2002.

Building complex structure wells is an effective approach for economic development. Such reservoirs are characterized by low permeability, low abundance, bottom water, heavy oil, ultra-thinness, multilayer, coalbed methane, and natural gas reservoir [16,17]. Complex structure well technology has also been widely used recently for the development of buried hill reservoirs.

\section{(a) Low-Permeability Reservoir}

Hao [18] presented a new method that couples non-Darcy elliptical and Darcy radial flows to the horizontal wellbore in fractured reservoirs to predict and optimize the productivity of multiple transverse fractured horizontal wells in ultralow- permeability reservoirs. Yu [19] compared the difference between the development effects of low-permeability reservoir in multi-fractured horizontal wells and that in fishbone wells. Bigno [20] studied horizontal and multilateral well technology to develop low-permeability reservoirs.

\section{(b) Bottom Water Reservoir}

Zhou [21] studied horizontal well water flooding performance and its influencing factors and was the first to illustrate the water flooding patterns of horizontal wells in bottom water reservoir.

\section{(c) Heavy-Oil Reservoirs}

Horizontal and multilateral wells are designed to develop heavy-oil reservoirs because of the advantages of these wells in terms of enhanced oil recovery $[3,22]$.

\section{(d) Ultra-Thin Reservoir}

Two fishbone wells have been drilled in the reservoir of which the thickness is $1.5 \mathrm{~m}$ in Daqing oilfield that is currently the thinnest reservoir with fishbone wells, and many technical problems arising from drilling in an ultra-thin oil layer have been solved successfully $[2,23]$.

\section{(e) Multilayer Reservoir}

A semi-analytical model of multilateral well was presented by Yan [24]. This model can predict the production performance of a complex structure well in multilayer reservoirs with different porosities and anisotropic permeabilities, obtain information about reservoir connectivity, and estimate well and reservoir properties in a multilayer system.

\section{(f) Coalbed Methane Reservoirs}

Maricic [25] compared the drilling cost of dual-, tri-, and quad-laterals with fishbone wells and studied the total length of horizontal wells, as well as the distance between laterals in these configurations.

\section{(g) Gas-Drive Reservoir}

Rivera [26] established multilateral well technologies, analyzed the application of multilateral well technology in reservoirs, and suggested that the behavior of multilateral wells is similar to the solution gas-drive mechanism.

\section{(h) Buried Hill Reservoir}

The buried hill reservoirs are in fact remnant topography (irregular unconformity surfaces) that has been buried beneath younger sediments. Many of the onshore Chinese basins contain buried hill reservoirs [27]. The application of multilateral wells in buried hill reservoirs achieved satisfactory development performance. Such application has become a common approach to the development of similar reservoirs because of the significant economic benefit provided by multilateral wells [28]. A buried hill reservoir features developed fractures, good connection, and thick layer [29], resulting in low productivity and poor development effect when developed with vertical wells. Given the problems existing in developing reservoirs with vertical wells, considerable research has been conducted on the mechanisms of complex structure wells, parameters for optimizing stereo injection-production, productivity, and influencing factors of the development of horizontal wells [30-35]. The well pattern of vertical and horizontal wells was proposed, which contributed to the improvement of buried hill reservoir development.

This paper reports on the best well pattern and development law for buried hill reservoirs through experiments. The fabrication method of the experimental model and wellbore presetting are proposed. Based on the target reservoir, a similar experimental model is established with different well pat- 
terns, through which water flooding experiments can be conducted to examine the development effect. Combined with the development effect, the best complex structure well pattern is determined to provide theoretical and technical support for the further enhancement of oil recovery.

\section{Fabrication Method of Experimental Model}

\subsection{Principle of Model Fabrication}

A fractured reservoir consists of a fracture system and a matrix system. A vertically crossed fracture network (as shown in Fig. 1) can represent the distribution of actual fractures.

By discretization, the experimental model is established by adhering cubic blocks with size of $5 \mathrm{~cm} \times 5 \mathrm{~cm} \times 5 \mathrm{~cm}$ fabricated by crude outcropping sand. The bonded face between blocks adhered by points indicates a fracture, whereas a reticulate indicates an inactive fracture. Fracture properties, such as permeability and porosity, can be controlled quantitatively by adjusting fracture density.

The width of fracture is affected by manufacturing precision of unit blocks and the volume of binder. To control the fracture width, firstly, we must be sure that the manufacturing precision of the unit blocks is precise enough. The outcrop rocks are made into cubic blocks with the size of $50 \mathrm{~mm}$ by infrared automatic cutting machine, and the error of the size is less than $1 \%$ after the selection of using vernier caliper. Based on the strict precision control of unit blocks manufacturing and selection, all the sizes of the unit blocks are equal with each other, and therefore, the fracture surfaces are parallel and then control the volume of binder strictly. The depth of binder penetrates into the unit blocks are limited and equal due to high viscosity of binder and low permeability of matrix. The volume of binder is controlled precisely by dispenser, so that the thicknesses of binder between the two bonded surfaces are the same. As a result, the widths of fractures are the same when the precision of unit blocks manufacturing and the volume of binder are controlled.

\subsection{Design of Fracture System}

A Cartesian coordinate system $(x, y, z)$ is established with three axes parallel to the three principal directions of anisotropic permeability. The fracture permeability at each direction is supposed to be $K_{x}, K_{y}, K_{z}$, whereas the fracture density perpendicular to each direction is $N_{x}, N_{y}, N_{z}$, respectively. The formulas of fracture permeability are [36]

$$
\begin{aligned}
& \bar{K}_{e x}=N_{x} k\left[\begin{array}{ccc}
0 & 0 & 0 \\
0 & 1 & 0 \\
0 & 0 & 1
\end{array}\right], \bar{K}_{e y}=N_{y} k\left[\begin{array}{ccc}
1 & 0 & 0 \\
0 & 0 & 0 \\
0 & 0 & 1
\end{array}\right], \\
& \bar{K}_{e z}=N_{z} k\left[\begin{array}{lll}
1 & 0 & 0 \\
0 & 1 & 0 \\
0 & 0 & 0
\end{array}\right]
\end{aligned}
$$

The total anisotropic permeability in this fracture system is given by Eq. (2)
Fig. 1 Structure of dual porous media

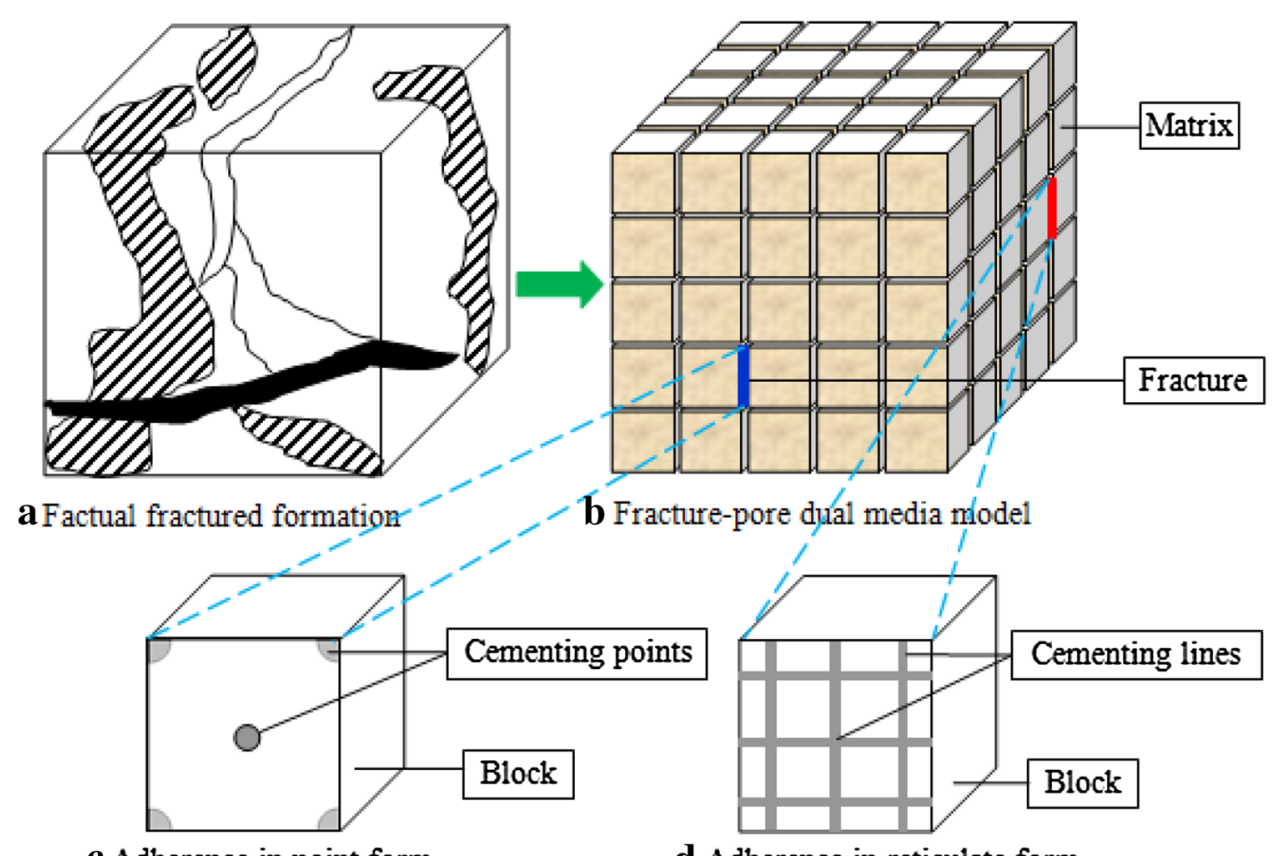

d Adherence in reticulate form

c Adherence in point form 


$$
\begin{aligned}
\bar{K}_{e} & =\bar{K}_{e x}+\bar{K}_{e y}+\bar{K}_{e z} \\
& =k\left[\begin{array}{ccc}
N_{y}+N_{z} & 0 & 0 \\
0 & N_{x}+N_{z} & 0 \\
0 & 0 & N_{x}+N_{y}
\end{array}\right]
\end{aligned}
$$

The ratio among principal values of permeability at each direction is

$$
k_{x}: k_{y}: k_{z}=\left(N_{y}+N_{z}\right):\left(N_{x}+N_{z}\right):\left(N_{x}+N_{y}\right)
$$

This ratio can be transformed as

$$
\begin{aligned}
N_{x}: N_{y}: N_{z}= & \left(k_{y}+k_{z}-k_{x}\right):\left(k_{z}+k_{x}-k_{y}\right) \\
& :\left(k_{x}+k_{y}-k_{z}\right)
\end{aligned}
$$

Formula (4) represents the condition of fracture distribution, considering the anisotropy of permeability.

\subsection{Realization of Wellbore and Well Pattern Combination}

\subsubsection{Method for Wellbore Presetting}

A wellbore is discretized into segments by drilling wellbores in cubic blocks and then adhering them to form the entire wellbore, as shown in Fig. 2. Hence, different wells, including vertical, horizontal, and fishbone wells, can be preset within the model.

\subsubsection{Plugging of Preset Wellbore}

Elastic pipelines, which are expandable and retractable with pressure variation, are placed in the wellbore. The fluid pressure in elastic pipelines is controlled by an external pressure source to achieve plugging and unblocking, as shown in Fig. 3. By selectively plugging wellbores in the model, the target well pattern can be realized.
Fig. 2 Diagram of presetted wellbore

Fig. 3 Plugging of presetted wellbore
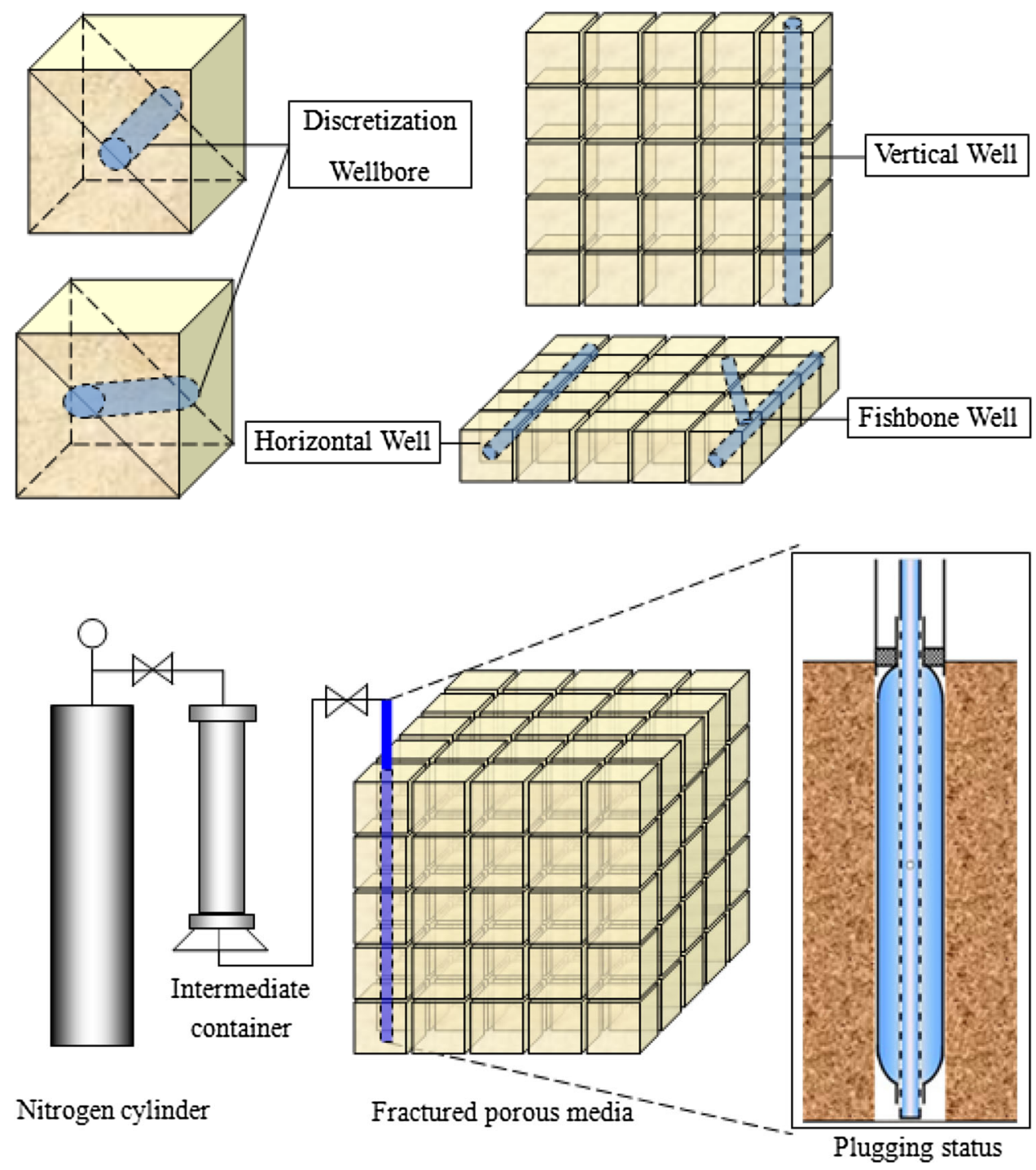


\section{Similarity Principle of Fractured Reservoir}

The experimental conditions for water flooding in fractured reservoir are assumed as follows [34]: (1) The reservoir media are characterized by dual porosity and single permeability with matrix and fractures for fluid storage and a fracture system as a percolation channel; (2) imbibition exists between the matrix and fractures, and capillary pressure within fractures is ignored; (3) the influence of oil-water gravity difference is considered; (4) rock media and fracture permeability are anisotropic; and (5) compressibility of fluid and rock is neglected.

\subsection{Mathematical Model}

The motion equations for the fracture system are given by

$$
\left\{\begin{array}{l}
\text { water : } \quad \vec{v}_{\mathrm{w}}=-\mathbf{A}_{\mathbf{w}} \cdot \nabla \Phi_{\mathrm{w}} \\
\text { oil : } \quad \vec{v}_{\mathrm{o}}=-\mathbf{A}_{\mathbf{o}} \cdot \nabla \Phi_{\mathrm{o}}
\end{array}\right.
$$

where $\vec{v}$ is flow velocity and the subscripts o, w denote oil and water, respectively. $\mathbf{A}_{\mathbf{w}}$ and $\mathbf{A}_{\mathbf{o}}$ are the tensors of water and oil mobility, respectively, and are formulated as

$$
\mathbf{A}_{\mathbf{o}}=\frac{\mathbf{K} K_{\mathrm{ro}}}{\mu_{\mathrm{o}}}, \quad \mathbf{A}_{\mathbf{w}}=\frac{\mathbf{K} K_{\mathrm{rw}}}{\mu_{\mathrm{w}}}
$$

$\mathbf{K}$ is the tensor of anisotropic permeability. $K_{\mathrm{ro}}$ and $K_{\mathrm{rw}}$ are the relative permeabilities of oil and water, respectively. $\mu_{\mathrm{o}}$ and $\mu_{\mathrm{w}}$ are the velocities of oil and water, respectively. $\Phi_{\mathrm{o}}$ and $\Phi_{\mathrm{w}}$ are potentials of the oil and water phases, respectively, and are formulated as

$\Phi_{\mathrm{o}}=p+\gamma_{\mathrm{o}} D, \quad \Phi_{\mathrm{w}}=p+\gamma_{\mathrm{w}} D$

where $p$ is pressure, $\gamma$ is specific gravity, and $D$ is depth.

The material balance equations for the fracture system are

$$
\left\{\begin{array}{l}
\text { water }: \quad \nabla \cdot \vec{v}_{\mathrm{w}}-q_{\mathrm{w}}=-\Phi \frac{\partial S_{\mathrm{w}}}{\partial t} \\
\text { oil }: \quad \nabla \cdot \vec{v}_{\mathrm{o}}-q_{\mathrm{o}}=-\Phi \frac{\partial S_{\mathrm{o}}}{\partial t}
\end{array}\right.
$$

where $q$ and $S$ are imbibition rate and saturation, respectively, and $\Phi$ is the porosity.

The imbibition equation between matrix and fracture is formulated as

$$
\begin{aligned}
& q_{\mathrm{o}}=R \cdot \frac{\ln 2}{T_{\mathrm{a}}}[ S_{\mathrm{w}}(x, y, z, t) \\
&\left.\quad-\frac{\ln 2}{T_{\mathrm{a}}} \int_{0}^{t} S_{\mathrm{w}}(x, y, z, \tau) \mathrm{e}^{\frac{\ln 2}{T_{\mathrm{a}}}(\tau-t)} \mathrm{d} \tau\right] \\
&=R \cdot \frac{\ln 2}{T_{\mathrm{a}}} \int_{0}^{t} \frac{\partial S_{\mathrm{w}}}{\partial \tau} \cdot \mathrm{e}^{\frac{\ln 2}{T_{\mathrm{a}}}(\tau-t)} \mathrm{d} \tau
\end{aligned}
$$

where $R$ is the movable oil volume per unit matrix volume; $T_{\mathrm{a}}$ is the half-cycle of imbibition; $t$ is time; $\tau$ is the intermediate variable; and $x, y, z$ are the coordinates in rectangular space of the reservoir.
The formulas for relative permeability equations of oil and water, without considering the capillary for fracture, are given by

$K_{\mathrm{rw}}=S_{\mathrm{w}}, \quad K_{\mathrm{ro}}=1-S_{\mathrm{w}}$

The naturally satisfied equations are

$S_{\mathrm{o}}+S_{\mathrm{w}}=1, \quad q_{\mathrm{w}}+q_{\mathrm{o}}=0$

The initial conditions are

$$
\begin{gathered}
\Phi_{\mathrm{o}}(x, y, z, t=0)=\Phi_{i}, \quad \Phi_{\mathrm{w}}(x, y, z, t=0)=0, \\
S_{\mathrm{W}}(x, y, z, t=0)=0
\end{gathered}
$$

where $\Phi_{i}$ is the initial potential distribution.

Boundary conditions: reservoir boundary $\Gamma$ is a closed boundary with a normal boundary $n$,

$$
\left.\frac{\partial \Phi_{\mathrm{o}}}{\partial n}\right|_{\Gamma}=0,\left.\quad \frac{\partial \Phi_{\mathrm{w}}}{\partial n}\right|_{\Gamma}=0
$$

A wellbore is assumed to have fixed injection-production pressure difference, formulated as

$p\left(\vec{r}_{\text {inj }}, t\right)-p\left(\vec{r}_{\text {pro }}, t\right)=\Delta p$

where $r_{\mathrm{w}}$ is the wellbore radius; $\vec{r}_{\text {inj }}=(x, y, z)_{\text {inj }}$ and $\vec{r}_{\text {pro }}=(x, y, z)_{\text {pro }}$ are the vector coordinates on the injection and production wellbore, respectively; and $\Delta p$ is injection and production differential pressure.

Combining Eqs. (5)-(14), the water flooding mathematical model of fractured reservoir can be expressed by Eq. (15).

$$
\left\{\begin{array}{l}
\frac{\partial}{\partial x}\left[\left(K_{x} \cdot\left(1-S_{\mathrm{w}}\right)+\frac{\mu_{\mathrm{o}}}{\mu_{\mathrm{w}}} \cdot K_{x} S_{\mathrm{w}}\right) \cdot \frac{\partial \Phi_{\mathrm{w}}}{\partial x}\right] \\
\quad+\frac{\partial}{\partial y}\left[\left(K_{y} \cdot\left(1-S_{\mathrm{W}}\right)+\frac{\mu_{\mathrm{o}}}{\mu_{\mathrm{w}}} \cdot K_{y} S_{\mathrm{w}}\right) \cdot \frac{\partial \Phi_{\mathrm{W}}}{\partial y}\right] \\
\quad+\frac{\partial}{\partial z}\left[\left(K_{z} \cdot\left(1-S_{\mathrm{W}}\right)+\frac{\mu_{\mathrm{o}}}{\mu_{\mathrm{w}}} \cdot K_{z} S_{\mathrm{w}}\right) \cdot \frac{\partial \Phi_{\mathrm{w}}}{\partial z}\right] \\
\quad-\frac{\partial}{\partial z}\left[K_{z} \cdot\left(1-S_{\mathrm{w}}\right) \Delta \gamma\right]=0 \\
\frac{\partial}{\partial x}\left[\frac{K_{x} \cdot S_{\mathrm{W}}}{\mu_{\mathrm{w}}} \cdot \frac{\partial\left(\Phi_{\mathrm{o}}-\Phi_{i}\right)}{\partial x}\right]+\frac{\partial}{\partial y}\left[\frac{K_{y} \cdot S_{\mathrm{W}}}{\mu_{\mathrm{w}}} \cdot \frac{\partial\left(\Phi_{\mathrm{o}}-\Phi_{i}\right)}{\partial y}\right] \\
\quad+\frac{\partial}{\partial z}\left[\frac{K_{z} \cdot S_{\mathrm{W}}}{\mu_{\mathrm{w}}} \cdot \frac{\partial\left(\Phi_{\mathrm{o}}-\Phi_{i}\right)}{\partial z}\right] \\
\quad+\frac{\partial}{\partial z}\left(\frac{K_{z} \cdot S_{\mathrm{W}}}{\mu_{\mathrm{w}}} \cdot \Delta \gamma\right)-R \frac{\ln 2}{T_{\mathrm{a}}} \int_{0}^{t} \frac{\partial S_{\mathrm{w}}}{\partial \tau} \cdot \mathrm{e}^{-\frac{\ln 2}{T_{\mathrm{a}}}(t-\tau)} \mathrm{d} \tau=\Phi \cdot \frac{\partial S_{\mathrm{W}}}{\partial t} \\
\Phi_{\mathrm{o}}(x, y, z, 0)-\Phi_{i}=0, \quad \Phi_{\mathrm{w}}(x, y, z, 0)=0 \\
S_{\mathrm{w}}(x, y, z, 0)=0 \\
\left.\frac{\partial \Phi_{\mathrm{o}}}{\partial n}\right|_{\Gamma}=0,\left.\quad \frac{\partial \Phi_{\mathrm{w}}}{\partial n}\right|_{\Gamma}=0 \\
p\left(\vec{r}_{\mathrm{inj}}, t\right)-p\left(\vec{r}_{\mathrm{pro}}, t\right)=\Delta p
\end{array}\right.
$$


Table 1 Similarity criterion for simulation of water flooding in fractured anisotropic reservoir

\begin{tabular}{|c|c|c|c|}
\hline Similarity & Expressions & Definitions & Effects \\
\hline$\pi_{1}$ & $L_{x} / L_{y}$ & $\begin{array}{l}\text { Ratio of characteristic length in } x \text { direction to } \\
\text { characteristic length in } y \text { direction }\end{array}$ & Similarity of size \\
\hline$\pi_{2}$ & $L_{x} / L_{z}$ & $\begin{array}{l}\text { Ratio of characteristic length in } x \text { direction to } \\
\text { characteristic length in } z \text { direction }\end{array}$ & \\
\hline$\pi_{3}$ & $x / L_{x}$ & Dimensionless $x$ coordinate & Similarity of shape and space \\
\hline$\pi_{4}$ & $y / L_{y}$ & Dimensionless $y$ coordinate & \\
\hline$\pi_{5}$ & $z / L_{z}$ & Dimensionless $z$ coordinate & \\
\hline$\pi_{6}$ & $\bar{K}_{y} / \bar{K}_{x}$ & $\begin{array}{l}\text { Ratio of permeability in } y \text { direction to permeability } \\
\text { in } x \text { direction }\end{array}$ & Similarity of anisotropy of permeability \\
\hline$\pi_{7}$ & $\bar{K}_{z} / \bar{K}_{x}$ & $\begin{array}{l}\text { Ratio of permeability in } z \text { direction to permeability } \\
\text { in } x \text { direction }\end{array}$ & \\
\hline$\pi_{8}$ & $K_{x} / \bar{K}_{x}$ & Dimensionless permeability in $x$ direction & Similarity of heterogeneity of permeability \\
\hline$\pi_{9}$ & $K_{y} / \bar{K}_{y}$ & Dimensionless permeability in $y$ direction & \\
\hline$\pi_{10}$ & $K_{z} / \bar{K}_{z}$ & Dimensionless permeability in $z$ direction & \\
\hline$\pi_{11}$ & $\Phi / \bar{\Phi}$ & Dimensionless porosity & Similarity of heterogeneity of permeability \\
\hline$\pi_{12}$ & $r_{\mathrm{w}} / L_{x}$ & Ratio of well radius to characteristic length & Similarity of wellbore geometry parameters \\
\hline$\pi_{13}$ & $\bar{\mu}_{\mathrm{o}} / \bar{\mu}_{\mathrm{w}}$ & Ratio of oil-water viscosity & Similarity of viscous resistance of fluid flow \\
\hline$\pi_{14}$ & $L_{z} \cdot \Delta \bar{\gamma} / \Delta p$ & $\begin{array}{l}\text { Ratio of gravitational pressure difference to } \\
\text { injection-production pressure difference }\end{array}$ & Similarity of dynamics \\
\hline$\pi_{15}$ & $\bar{R} / \bar{\Phi}$ & Ratio of movable oil in matrix to movable oil in fractures & Similarity of reserves of matrix and fracture \\
\hline$\pi_{16}$ & $R / \bar{R}$ & $\begin{array}{l}\text { Dimensionless movable oil volume per unit matrix } \\
\text { volume }\end{array}$ & Similarity of relation between imbibition and flooding \\
\hline$\pi_{17}$ & $\bar{T}^{*} / T$ & $\begin{array}{l}\text { Ratio of characteristic time of imbibition to } \\
\text { characteristic time of flooding }\end{array}$ & Similarity of relation between imbibition and flooding \\
\hline$\pi_{18}$ & $T^{*} / \bar{T}^{*}$ & Dimensionless half-cycle of imbibition & Similarity of imbibition strength distribution \\
\hline$\pi_{19}$ & $t / T$ & Dimensionless time & Similarity of time and process \\
\hline$\pi_{20}$ & $\Phi_{\mathrm{w}} / \Delta p$ & Dimensionless water potential & Similarity of potential distribution \\
\hline$\pi_{21}$ & $\left(\Phi_{\mathrm{o}}-\Phi_{i}\right) / \Delta p$ & Dimensionless oil potential & \\
\hline$\pi_{22}$ & $S_{\mathrm{W}}$ & Dimensionless water & Similarity of saturation distribution \\
\hline
\end{tabular}

\subsection{Similarity Criteria}

Based on dimensional analysis and similarity principle [29, 35], a similarity criterion system is established. This system consists of 22 similarity criteria, as listed in Table 1.

\section{Water Flooding Experiment}

\subsection{Background of Factual Reservoir}

A fractured buried hill reservoir in Liaohe oilfield develops three groups of structural fractures, i.e., NE-NNE direction, NW direction, and approximately EW direction with permeabilities of $K_{1}=360.8 \times 10^{-3} \mu \mathrm{m}^{2}, K_{2}=213.3 \times$ $10^{-3} \mu \mathrm{m}^{2}$, and $K_{3}=80.5 \times 10^{-3} \mu \mathrm{m}^{2}$, respectively. Among the fractures, mid-high-angle fractures $\left(70^{\circ}-90^{\circ}\right)$ account for $32 \%$, oblique fractures $\left(20^{\circ}-70^{\circ}\right)$ account for $58.4 \%$, and low-angle fracture $\left(<20^{\circ}\right)$ account for $9.6 \%$. A $1 / 4$ unit of stereo five-spot well pattern in the target reservoir is selected to identify the best well pattern. Based on water flooding similarity criteria of the fractured reservoir, the experimental model is fabricated with vertical, horizontal, and fishbone wells. The development effect of different well patterns can be revealed by water flooding experiments.

\subsection{Distribution of Fractures}

According to the calculation method of permeability anisotropy [37], the ratio of anisotropic permeability in the $X, Y, Z$ direction is given by

$K_{x}: K_{y}: K_{z}=1: 1.05: 1.4$

Combining Eqs. (4) and (16), the number of fractures perpendicular to the $X, Y, Z$ directions are 10,9 , and 9, respectively. In practice, every bonded face perpendicular to the $X$ direction makes a fracture, which is the maximum fracture density in the model, whereas one fracture is made for 
every two bonded faces perpendicular to the $Z$ direction. The first, second, third, fourth, fifth, sixth, eighth, ninth, and tenth bonded faces perpendicular to the $Y$ direction are chosen to make nine fractures.

\subsection{Design of Well Patterns}

According to the similarity criteria, six wells are preset in the model, with $\mathrm{Z} 1$ and $\mathrm{Z} 2$ as vertical wells, $\mathrm{S} 1$ and $\mathrm{S} 2$ as horizontal wells, and Y1 and Y2 as fishbone wells with a single branch $30 \mathrm{~cm}$ long at a $25^{\circ}$ angle [intersection point of branches with main boreholes are $(4,11,21)$ and $(8,1,11)$, respectively]. The wells preset within the model are shown in Fig. 4.

Based on the objective of this research, the method mentioned in Sect. 2.3 is used to design five experimental schemes with the details shown in Table 2. Experiments are conducted under atmospheric temperature with a constant pressure difference of $0.27 \mathrm{~m}$ water column. The liquid production, water production, and the corresponding time are recorded, and the water cut is calculated. The experiment was terminated when the water cut reached $100 \%$.

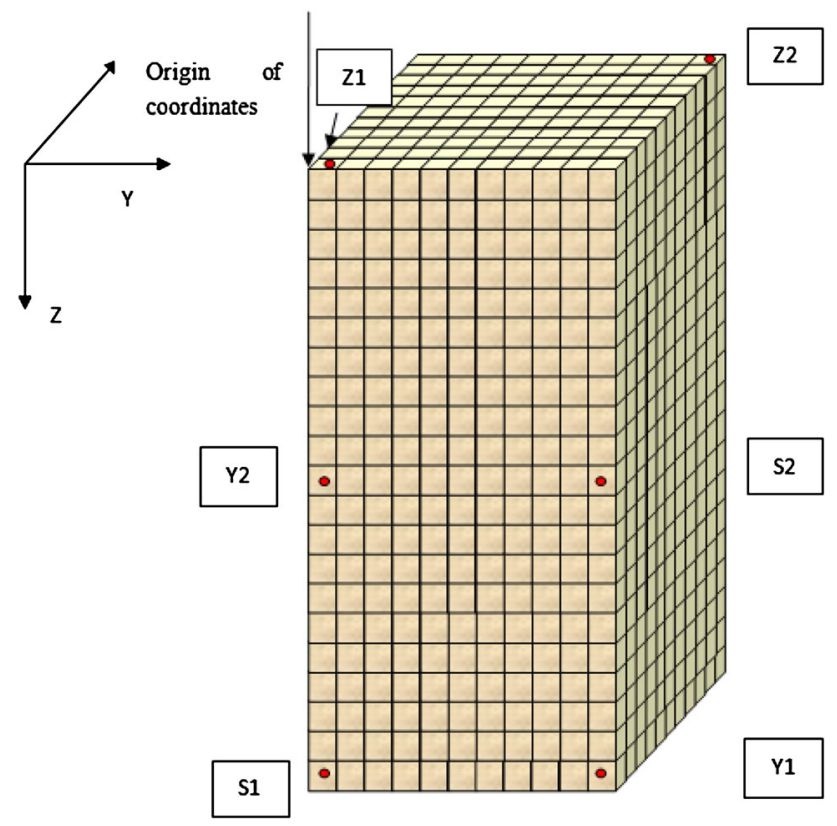

Fig. 4 Outline of wells presetted within the experimental model

\subsection{Processing and Selection of Rocks}

After nearly eight months of trial and selection, sandstone outcrops are selected and transported from the provinces of Hebei, Shanxi, Yunnan, and Sichuan. More than 300 core test experiments are conducted, and natural yellow sandstones are selected as the model-making materials. A total of 3,500 blocks, with a size error of less than $0.1 \mathrm{~mm}$ and an angle error of less than $0.5^{\circ}$, are selected from 6,000 cube blocks, which are processed from natural sandstone outcrops with a size of $5 \mathrm{~cm} \times 5 \mathrm{~cm} \times 5 \mathrm{~cm}$.

\subsection{Establishment of Similarity Experimental Model}

Two bonding methods are combined to establish the model with a developed high-angle fracture. Based on an actual buried hill reservoir in Liaohe oilfield, an experimental model with cubic blocks of $11 \times 11 \times 21=2,541$ is established according to the principle in Sect. 2.1. The manufacturing process is shown in Fig. 5. The length of a unit cubic block is $5 \mathrm{~cm}$, the size of the model is $55 \mathrm{~cm} \times 55 \mathrm{~cm} \times 105 \mathrm{~cm}$, and the fracture width is proximately $0.02 \mathrm{~cm}$, as shown in Fig. 6. A $\mathrm{PVC}$ pipe with $6 \mathrm{~mm}$ outer diameter and $4 \mathrm{~mm}$ inner diameter is selected for the wellbore, and one with an outer diameter of $4 \mathrm{~mm}$ and an inner diameter of $2.5 \mathrm{~mm}$ is selected for the pressure pipeline. A wellbore is a barefoot well completion, and simulated oil with a viscosity of $14.48 \mathrm{mPa}$ s and water with a viscosity of $1 \mathrm{mPa}$ s are selected as experimental fluids. The macroscopic model is shown in Fig. 7.

The parameters of target reservoir and experimental model are listed in Table 3. The compositions of injected water are as shown in Table 4. Hydrocarbon, wax, resin, and asphaltene contents in crude oil are 52.03, 34.23, and $13.74 \%$, respectively.

\section{Analysis and Discussions}

\subsection{Comparison with Numerical Simulation}

The numerical model is established using eclipse. Cartesian coordinates, block center grid, black oil simulator, and laboratory units are selected to establish a dual porosity single
Table 2 Experiment design for different cases

Horizontal well S2' is well Y2 with its branch plugged, and horizontal well $\mathrm{S}^{\prime}$ is well $\mathrm{Y} 1$ with its branch plugged

\begin{tabular}{llll}
\hline No. of cases & Well pattern & Well & Remark \\
\hline Case 1 & Vertical well-fishbone well & $\mathrm{Z} 1, \mathrm{Z} 2$ & $\mathrm{Z} 1$ for injection, Z1 for production \\
Case 2 & Fishbone well-fishbone well & $\mathrm{Y} 1, \mathrm{Y} 2$ & $\mathrm{Y} 1$ for injection, Y2 for production \\
Case 3 & Horizontal well-fishbone well & $\mathrm{S}^{\prime}, \mathrm{Y} 2$ & $\mathrm{~S}^{\prime}$ for injection, Y2 for production \\
Case 4 & Fishbone well-horizontal well & $\mathrm{Y} 1, \mathrm{~S} 2^{\prime}$ & Y1 for injection, S2' for production \\
Case 5 & Horizontal well-horizontal well & $\mathrm{S} 1, \mathrm{~S} 2$ & S1 for injection, S2 for production \\
\hline
\end{tabular}


Fig. 5 Manufacture process for experimental model
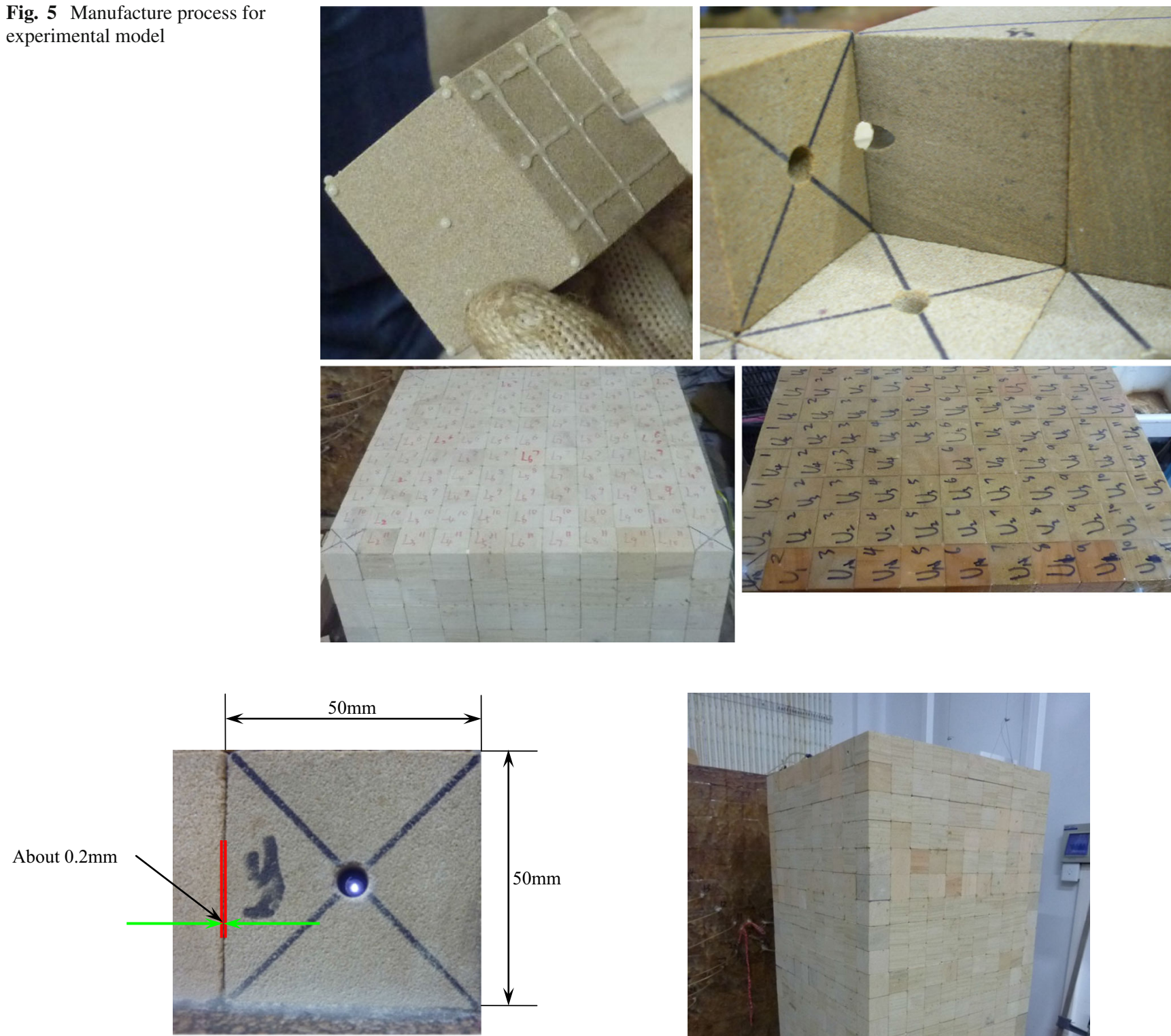

Fig. 6 Structure of dual porous media

permeability model. The parameters of numerical model and experimental model, such as the size and properties, are all the same. The gridding number is $11 \times 11 \times 42=5,042$. In vertical direction, the 1 st to 21 st are the matrix systems, the 22nd to 42 nd are the fracture systems, and the gridding size are $5 \mathrm{~cm} \times 5 \mathrm{~cm} \times 5 \mathrm{~cm}$. Therefore, the experimental model established method could be verified by the software based on experimental data matching.

1. Permeability of fracture is much greater than that of matrix. Under the experimental pressure, fluid flow through the reservoir takes place only in the fracture network with the matrix blocks acting as sources. This is regarded as a dual porosity single permeability system,

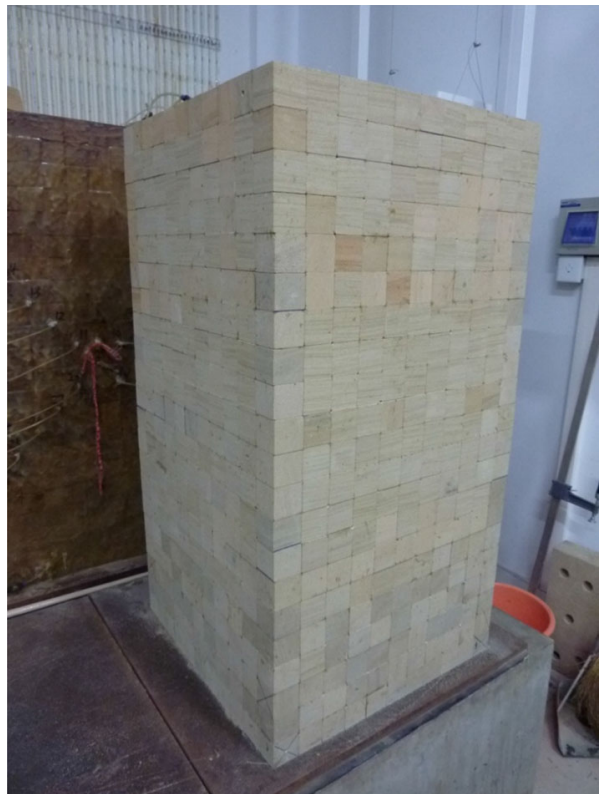

Fig. 7 Experimental model

so dual porosity single permeability model is chosen in numerical model.

2. In water-wet fractured reservoirs, the matrix rock has a positive water-oil capillary pressure. After water is introduced into the fracture, the water flows under capillary forces into the matrix system to displace oil. Therefore, imbibition between matrix and fracture should be consid- 
Table 3 Parameters of target reservoir and experimental model

\begin{tabular}{|c|c|c|c|}
\hline Parameters & Field & Model & Notes \\
\hline Size & $250 \mathrm{~m} \times 250 \mathrm{~m} \times 500 \mathrm{~m}$ & $0.55 \mathrm{~m} \times 0.55 \mathrm{~m} \times 1.05 \mathrm{~m}$ & $\pi_{1}-\pi_{5}$ \\
\hline Well radius $(\mathrm{m})$ & 0.14 & 0.06 & $\pi_{6}$ \\
\hline Fracture permeability in $x$ direction $(\mathrm{mD})$ & 121.18 & 3,836 & $\pi_{7}-\pi_{11}$ \\
\hline Fracture permeability in $y$ direction $(\mathrm{mD})$ & 127.24 & 4,027 & \\
\hline Fracture permeability in $z$ direction $(\mathrm{mD})$ & 169.65 & 5,370 & \\
\hline Matrix porosity $(\%)$ & 2.84 & 16 & $\pi_{12}$ \\
\hline Fracture porosity $(\%)$ & 0.72 & 1.0 & \\
\hline Matrix irreducible water saturation (\%) & 47.8 & 54.2 & $\pi_{13}-\pi_{22}$ \\
\hline Matrix residual oil saturation (\%) & 30 & 21.8 & \\
\hline Movable oil ratio of matrix and fracture & $1.3: 1$ & $1.3: 1$ & \\
\hline Oil viscosity (mPa s) & 7.72 & 14.48 & \\
\hline Water viscosity (mPa s) & 0.533 & 1 & \\
\hline Oil-water viscosity ratio & 14.48 & 14.48 & \\
\hline Water density $\left(\mathrm{g} / \mathrm{cm}^{3}\right)$ & 1 & 1 & \\
\hline Oil density $\left(\mathrm{g} / \mathrm{cm}^{3}\right)$ & 0.82 & 0.915 & \\
\hline Water-oil density difference $\left(\mathrm{g} / \mathrm{cm}^{3}\right)$ & 0.18 & 0.085 & \\
\hline Injection-production pressure & $16 \mathrm{MPa}$ & $0.27 \mathrm{~m}$ water column & \\
\hline
\end{tabular}

Table 4 Compositions of injected water

\begin{tabular}{lrlr}
\hline Ion & $\begin{array}{l}\text { Concentration } \\
(\mathrm{mg} / \mathrm{L})\end{array}$ & Ion & \multicolumn{1}{c}{$\begin{array}{l}\text { Concentration } \\
(\mathrm{mg} / \mathrm{L})\end{array}$} \\
\hline $\mathrm{K}^{+}+\mathrm{Na}^{+}$ & 782.69 & $\mathrm{SO}_{4}^{2-}$ & 9.61 \\
$\mathrm{Ca}^{2+}$ & 8.02 & $\mathrm{HCO}_{3}^{-}$ & $1,452.58$ \\
$\mathrm{Mg}^{2+}$ & 2.43 & $\mathrm{CO}_{3}^{2-}$ & 95.22 \\
$\mathrm{Cl}^{-}$ & 327.93 & Salinity & $2,678.48$ \\
\hline
\end{tabular}

ered, while the fracture cells usually have zero capillary pressure.

Wettability is reflected by oil-water relative permeability curve. In the reservoir, the minimum saturation of wetting phase is greater than that of non-wetting phase; the relative permeability of non-wetting phase increases with its saturation faster than wetting phase. Therefore, the reservoir wettability of numerical model can be determined by the characteristics of the relative permeability curve. Because the reservoir is hydrophilic reservoir, a hydrophilic relative permeability curve is adopted in numerical model as shown in Fig. 8. Relative permeability curve of fracture system is shown in Fig. 9.

3. Due to its great thickness of buried hill reservoirs, fluid gravity must be considered.

4. The fracture permeability of actual reservoir is anisotropic; therefore, the fracture permeability of the experimental model and numerical models is anisotropic.
5. Compressibility of the fluid and rock is ignored due to tiny pressure fluctuation range, when well pattern variation is the only factor to be considered.

Compared the experimental results with the numerical simulation, we find that the experiments are closer to that of the numerical simulation, which indicates the reliability of the experimental method.

\subsection{Macroscopic Development Law}

\subsubsection{Liquid Rate}

Figure 10 indicates that under a pressure difference of 0.27 $\mathrm{m}$ water column, the liquid rate of Case 2 is the highest, followed by Case 3, with that of Case 1 being the lowest.

The reason for the difference in liquid rate lies in the different drilling ratios of fractures for different well types. The liquid rate of the vertical well is the lowest because of the lowest drilling ratio of fractures in a buried hill reservoir, in which mid-high-angle fractures developed as dominant channels for oil-water migration. By contrast, the ratio of drilling through fractures, as well as the drainage volume of horizontal wells, is relatively higher under lower injectionproduction pressure difference. The controlling area and drilling ratio of fishbone wells are even larger because of the branch, which shortens the distance between the injection and production wells, resulting in an increasing pressure gradient. 
Fig. 8 Relative permeability curve of matrix and capillary pressure

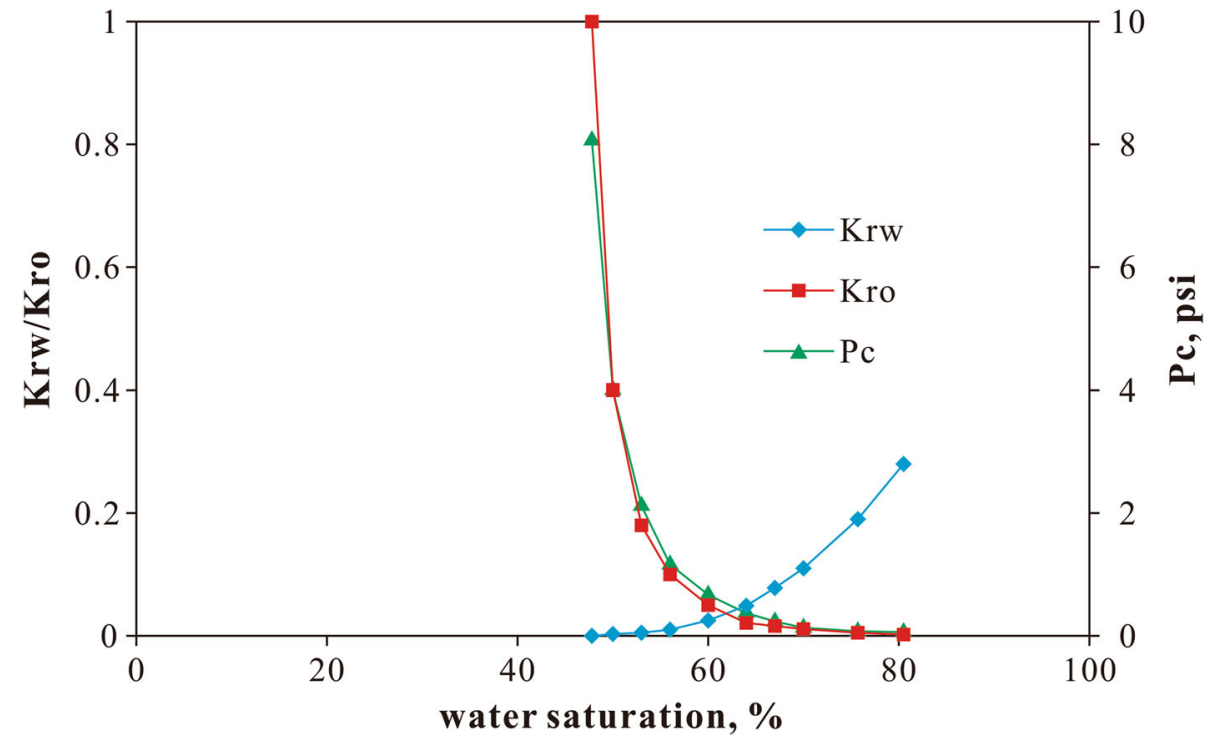

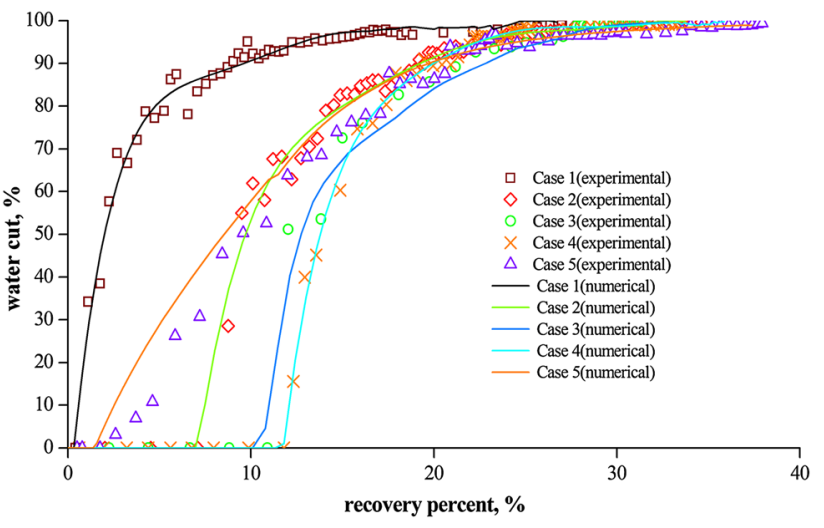

Fig. 11 Variations of water cut with recovery by different well patterns

For Case 1, the oil-water front breaks through along the bottom plane of the reservoir, whereas in the other cases, which involve the stereo injection-production of complex structure wells, the oil-water fronts are restrained by gravity, which prolongs the water-free oil production period. The branches of the fishbone well expand the injection area, causing injected water to migrate gently. Once water breakthrough occurs in the fishbone well, the water cut will increase more rapidly than that in horizontal wells.

\subsubsection{Oil Recovery Percentage}

The oil recovery percentage of water-free oil production period from highest to lowest is in the order of Case 4, 3, 2,5 , and 1 , with oil recoveries of $11.8,10.9,7.1,2.6$, and $1.1 \%$, respectively. The final oil recoveries are $33.93,31.40$, $34.60,37.94$, and $27.48 \%$. The results show that the vertical well features the lowest oil recovery. Compared with vertical wells, complex structure wells have larger areas of conmost rapid increase in water cut, followed by Cases 2, 3, and 4 , with that of Case 5 being the slowest. 
tact with the reservoir and a higher ratio of drilling through fractures, which contribute to the development advantages. Fishbone wells tend to make the oil-water front gentler when the percolation direction is perpendicular to the plane determined by the mother bore and its branch, which induces gentle water coning. Therefore, by making the plane determined by the mother bore and its branch vertical to the percolation direction, satisfactory development can be achieved by using a fishbone well.

\section{Conclusions}

- The method for the establishment of the experimental model and wellbore presetting are proposed according to discretization. Different well patterns can be realized by selectively plugging different wells in the model.

- Combined with target reservoir, the similarity experimental model is designed and fabricated according to the water flooding similarity principle of a fractured reservoir, which fully accords with similarity, such that the development process of a fractured reservoir can be simulated.

- Numerical model is established which the parameters are the same with experimental model. And reliability of the experimental model establishing method is verified by the software based on experimental data matching.

- The results of experiments and numerical simulation illustrate that complex structure well patterns can contribute to higher oil recovery compared with vertical well patterns in buried hill reservoirs. Considering the experimental index (liquid rate, water cut, and oil recovery), the horizontal-horizontal well pattern is recommended.

- For fishbone wells, if the plane determined by the mother bore and its branch is vertical to the percolation direction, the oil-water front will be gentle, and injected water will cone gently.

Acknowledgments The authors would like to express their appreciation for the financial support received from Nation Natural Science Foundation of China (No. 51374222) and National Science and Technology Major Project "Complicated oil and gas geology and EOR Technology" (No. 2011ZX05009-004-001).

Open Access This article is distributed under the terms of the Creative Commons Attribution License which permits any use, distribution, and reproduction in any medium, provided the original author(s) and the source are credited.

\section{References}

1. Delamaide, E.; Renard, G.; Kalaydjian, F.; Lobey, O.; Duquerroix, J.P.: How to choose the best tool in the new toolbox of reservoir engineers: complex structure well architectures. In: SPE interna- tional conference on horizontal well technology held in Calgary, Canada, SPE 37083, 18-20 Nov 1996

2. Xing, G.Y.; Guo, F.X.; Song, C.; Sun, Y.C.; Yu, J.; Wang, G.: Fishbone well drilling and completion technology in ultra-thin reservoir. In: IADC/SPE Asia Pacific drilling technology conference and exhibition held in Tianjin, China, IADC/SPE 155958, 9-11 July 2012

3. Cuadros, J.; Ossa, N.; Cuadros, G.; Rojas, E.: Horizontal well placement optimization for heavy oil production in girasol field. In: The Trinidad and Tobago energy resources conference held in Port of Spain, Trinidad, SPE 132884, 27-30 June 2010

4. John, L.S.; Gregory, D.Y.; Robert, J.K.; Carl, M.; Tony, L.; Petrozuata, C.A., Jeffery H.: Multilateral-horizontal wells increase rate and lower cost per barrel in the Zuata field; Faja; Venezuela. In: SPE international thermal operations and heavy oil symposium held in Porlamar, Margarita Island, Venezuela, SPE 69700, 12-14 March 2001

5. Raghavan, R.; Joshi, S.D.: Productivity of multiple drainholes or fractured horizontal wells. In: SPE Eastern regional meeting held in Columbus, OH, SPE 21263, Oct 31-Nov 21990

6. Larsen, L.: Productivity computations for multilateral; branched; and other generalized and extended well concepts. In: SPE annual technical conferences and exhibition held in Denver, USA, SPE 36754, 6-9 Oct 1996

7. Fan, Y.P.; Han, G.Q.; Yang, C.C.: Production forecast for herringbone well and optimum configuration of lateral holes. Acta Pet. Sin. 27(4), 101-104 (2006)

8. Guo, B.; Sun, K.; Ghalambor, A.: Well Productivity Hand Book. pp. 226-230. Gulf Publishing Company, Houston, TX (2008)

9. Yang, X.S.; Liu, C.X.; Yan, J.; Wang, W.H; Shi, Z.L.; Jia, Y.: Research on productivity law of herringbone multilateral gas well. Acta Pet. Sin. 29(5), 727-733 (2008)

10. Jamil, A.T.; Shamsuddin, S.; Bevan, Y.: Simulation optimization of wells with complex architecture. In: Offshore technology conference held in Houston, Texas, USA, OTC 20131, 4-7 May 2009

11. Crumpton, P.I.; Habiballah, W.A.; Wardell-Yerburgh, P.G.; Nasser, K.A.; Faleh, A.A.: Multilateral-complex structure well optimization. In: SPE reservoir simulation symposium held in The Woodlands, Texas, USA, SPE 140882, 21-23 Feb 2011

12. Zhang, S.M.; Zhou, Y.J.; Song, Y.; Wan, H.Y.; An, Y.S.; Xu, Q.; Dong, Z.G.: Design optimization for the horizontal well pattern with herringbone-like laterals. Pet. Explor. Dev. 38(5), 606$612(2011)$

13. Jiang, H.F.; Sui, J.; Pang, Y.M.; Zhang, G.L.; Liu, Y.T.: Technique of exceptionally low abundance oil reservoir development by horizontal wells and its application. Pet. Explor. Dev. 33(3), 364368 (2006)

14. Al-Muntasheri, G.A.: Conformance control with polymer gels: what it takes to be successful. Arab. J. Sci. Eng. 37(4), 1131$1141(2012)$

15. Kader, A.K.A.; Kordik, P.; Khalil, A.; Mekkawi, M.; El-Bohoty, M.; Rabeh, T.; Refai, M.K.; El-Mahdy, A.: Interpretation of geophysical data at EL Fayoum-Dahshour Area, Egypt using three dimensional models. Arab. J. Sci. Eng. 38(7), 1769-1784 (2013)

16. Zhou, H.M.; Chang, X.J.; Hao, J.M.; Zheng, J.M.: Horizontal well development technique and its practice for complex faultblock reservoirs in Jidong oilfield. Pet. Explor. Dev. 33(5), 622629 (2006)

17. Zhou, Y.J.: Advances on special structure drilling development techniques in Shengli oilfield. Pet. Explor. Dev. 35(3), 318329 (2008)

18. Hao, M.Q.; Hu, Y.L.; Liu, X.; Wei, C.J.; Zhuang, Y.T.: Predicting and optimizing the productivity of multiple transverse fractured horizontal wells in ultra-low permeability reservoirs. IPTC; 16891 (2013) 
19. Yu, X.C.; Guo, B.Y.; Ai, C.; Bu, Z.D.: A comparison between multi-fractured horizontal and fishbone wells for development of low-permeability fields. In: SPE Asia Pacific oil and gas conference and exhibition held in Jakarta, Indonesia, SPE 120579, 4-6 Aug 2009

20. Bigno, Y.; Al-Bahry, A.; Melanson, D.D.; Al-Hasani, S.; Senger, J.C.; Henning, R.: Multilateral waterflood development of a lowpermeability carbonate reservoir. In: SPE annual technical conference and exhibition held in New Orleans, Louisiana, SPE 71609, 30 Sept-3 Oct 2001

21. Zhou D.; Jiang T.; Feng J.; Bian W.; Liu Y.: Research of water flooded performance and pattern in horizontal well with bottomwater drive reservoir. In: The petroleum society's 5th Canadian international petroleum conference (55th annual technical meeting), Calgary, Alberta, Canada, PETSOC 2004-093, 8-10 June 2004

22. Fipke, S.; Celli, A.: The use of multilateral well designs for improved recovery in heavy-oil reservoirs. In: IADC/SPE drilling conference held in Orlando, Florida, USA, SPE 112638, 4-6 March 2008

23. Liu, X.P.; Zhang, Z.S.; Cui, G.X.; Wang, J.L.; Yi, F.X.: Inflow performance relationship of a herringbone multilateral well. Acta Pet. Sin. 21(6), 57-60 (2000)

24. Yan, P.; Medhat, M.K.; Jitendra, K.: Applications of a semianalytical model of multilateral wells in multilayer reservoirs. In: SPE western regional meeting held in San Jose, California, USA, SPE 121335, 24-26 March 2009

25. Maricic, N.; Mohaghegh, S.D.; Artun, E.: A parametric study on the benefits of drilling horizontal and multilateral wells in coalbed methane reservoirs. In: SPE annual technical conference and exhibition held in Dallas, Texas, SPE 96018, 9-12 Oct 2005

26. Nestor, R.; Amit, K.; Arun, K.; Younes, J.: Application of multilateral wells in solution gas-drive reservoirs. In: SPE international petroleum conference and exhibition in Mexico held in Villahermosa, Mexico, SPE 74377, 10-12 Feb 2002

27. Zimmerle, W.: Petroleum Sedimentology. Kluwer Academic Publishers, Dordrecht (1995)
28. Lei, Y.; Chen, Y.; Shang, X.F.; Chen, Z.G.; Wu, S.; Zhao, Y.; Liu, Y.Q.: Application of multilateral wells in burial-hill migmatitic granite formation. In: IADC/SPE Asia Pacific drilling technology conference and exhibition held in Tianjin, China, IADC/SPE 155700, 9-11 July 2012

29. Xie, W.Y.; Meng, W.G.; Zhang, Z.W.; Li, X.G.; Chen, Z.Y.: Formation model of multi-stage fracture reservoirs inside the buried hills in Liaohe depression. Pet. Explor. Dev. 33(6), 649-652 (2006)

30. Ding, Z.P.; Liu, Y.T.; Zhang, Y.; Ao, K.: A quantitative 3D physical simulation method of waterflooding in fractured reservoirs. Pet. Sci. Technol. 30(12), 1250-1261 (2012)

31. Ding, Z.P.; Liu, Y.T.; Gong, Y.J.; Xu, N.: A new technique: fishbone well injection. Pet. Sci. Technol. 30(23), 2488-2493 (2012)

32. Ren, F.X.: Discussions on tridimensional reservoir development models. Pet. Explor. Dev. 39(3), 320-325 (2012)

33. Ding, Z.P.; Liu, Y.T.; Luo, Y.Y.; Ao, K.: Optimization design of horizontal well stereo injection and production in buried hill reservoirs. Well Test. 20(2), 49-51 (2011)

34. Zhao, L.X.; Jiang, M.H.; Zhao, X.F. et al.: Research on deliverability relationship of complicated horizontal well. J. Univ. Pet. China (Edition of Natural Science) 30(3), 77-80 (2006)

35. Wang, X.D.; Yu, G.D.; Li, Z.P.: Productivity of horizontal wells with complex branches. Pet. Explor. Dev. 33(6), 729-733 (2006)

36. Liu, Y.T.; Ding, Z.P.; Ao, K.; Zhang, Y.; Wei, J.: Manufacturing method of large-scale fractured porous media for experimental reservoir simulation. SPE J., 163108-PA (2013)

37. Liu, Y.T.; Ding, Z.P.; Qu, Y.G.; Zhao, C.J.: The characterization of fracture orientation and the calculation of anisotropic permeability parameters of reservoirs. Acta Pet. Sin. 32(5), 842-846 (2011) 